\title{
Comment on "Insignificant effect of climate change on winter haze pollution in Beijing" by Shen et al. (2018)
}

\author{
Run Liu ${ }^{1}$, Lu Mao ${ }^{2}$, Shaw Chen Liu ${ }^{1}$, Yuanhang Zhang ${ }^{2}$, Hong Liao ${ }^{3}$, Huopo Chen ${ }^{4}$, and Yuhang Wang ${ }^{5}$ \\ ${ }^{1}$ Institute for Environmental and Climate Research, Jinan University, Guangzhou, 510632, China \\ ${ }^{2}$ State Key Joint Laboratory of Environmental Simulation and Pollution Control, College of Environmental Sciences and \\ Engineering, Peking University, Beijing, 100871, China \\ ${ }^{3}$ School of Environmental Science and Engineering, Nanjing University of Information Science and Technology, \\ Nanjing, 210044, China \\ ${ }^{4}$ Institute of Atmospheric Physics, Chinese Academy of Sciences, Beijing, 100029, China \\ ${ }^{5}$ School of Earth and Atmospheric Sciences, Georgia Institute of Technology, Atlanta, GA 30332, USA
}

Correspondence: Shaw Chen Liu (shawliu@jnu.edu.cn)

Received: 26 February 2019 - Discussion started: 4 March 2019

Revised: 17 June 2019 - Accepted: 19 June 2019 - Published: 5 July 2019

The recent paper by Shen et al. (2018; referred to hereafter as SHEN) made a sweeping statement on the winter haze pollution in Beijing by claiming an "Insignificant effect of climate change on winter haze in Beijing". We argue that the paper contains three serious flaws. Any one of the three flaws can nullify the claim of SHEN.

SHEN made a sweeping statement on the winter haze pollution in Beijing by claiming an "Insignificant effect of climate change on winter haze in Beijing". While failing to acknowledge the large differences in the dataset used, analysis methodology, winter month selected, geographic region chosen, and period and timescale of study from the others, SHEN attempted to invalidate a number of previous studies, including Wang et al. (2015), Cai et al. (2017), Zou et al. (2017), and Li et al. (2018), which have suggested that climate change will worsen haze pollution in Beijing. In this context, our recent study (Mao et al., 2018) also suggested that global warming and other climate changes such as the El Niño-Southern Oscillation (ENSO) and Pacific Decadal Oscillation (PDO) contributed significantly to the trend as well as interannual variabilities in winter haze days in eastern China.

We have found three critical flaws in SHEN. First, SHEN did not conduct any evaluation of the accuracies or uncertainties of the projected changes in surface relative humidity $(\mathrm{RH})$ and meridional wind velocity at $850 \mathrm{hPa}$ (V850) in the RCP8.5 scenarios calculated by an ensemble of 32
Coupled Model Intercomparison Project Phase 5 (CMIP5) climate models for the 21st century (2080-2099 vs. 20002019). Here we evaluate the accuracies and uncertainties of the projected changes in RH of CMIP5 climate models by comparing changes in RH from historical simulations (19602017) of these climate models to observed values. Figure 1a shows the values of linear trends of annual average RH in Beijing-Tianjin-Hebei (BTH) calculated for 1960-2017 historical simulations by an ensemble of 17 CMIP5 climate models (Table 1). A few models show significant positive trends, but the average trend is only about $0.3 \%$ per decade. This small trend is consistent with the projected insignificant trends in 21st century (2080-2099 vs. 2000-2019) of RH in the RCP8.5 scenarios from an ensemble of 32 CMIP5 climate models as shown in Fig. 5c of SHEN. In contrast, the small positive trend is in stark disagreement with the average trend of about $-0.5 \%$ per decade observed at 25 meteorological stations in BTH between 1960 and 2017 (Fig. 1b).

The disagreement is further illustrated in Fig. $2 a$ and $b$, where the spatial distribution of trends of annual average RH in China calculated for 1960-2017 historical simulations by an ensemble of 17 CMIP5 climate models is compared to observed trends. The model trends are positive in the north and negative in southern China, while observed trends are uniformly negative and greater in value. These disagreements raise serious doubt on the validity of projected changes in $\mathrm{RH}$ in Beijing for the RCP8.5 scenarios by an ensemble of 32 
(a)

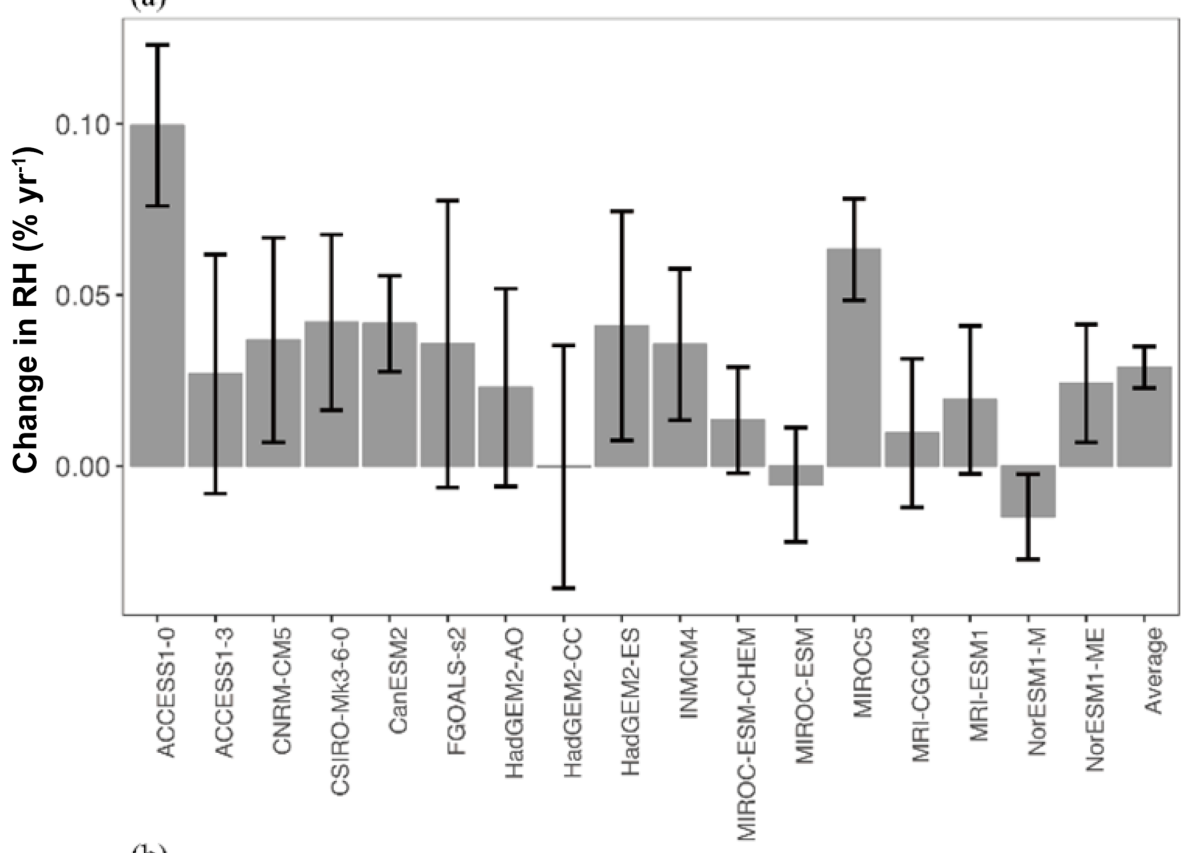

(b)

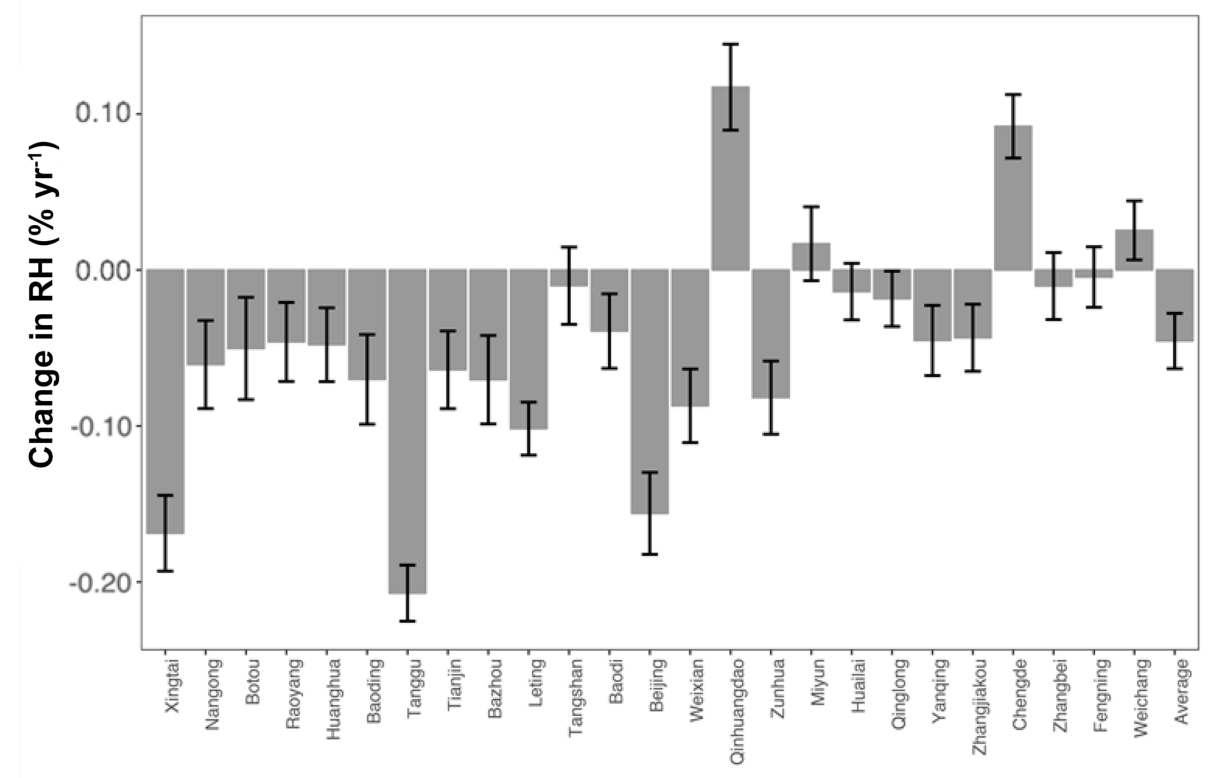

Figure 1. (a) Linear trends of annual average RH (in $\% \mathrm{yr}^{-1}$ ) in Beijing-Tianjin-Hebei (BTH), calculated for 1960-2017 historical simulations by an ensemble of 17 CMIP5 climate models; (b) same as (a) except derived from 25 China Meteorological Administration (CMA) meteorological stations in BTH region. 
(a)

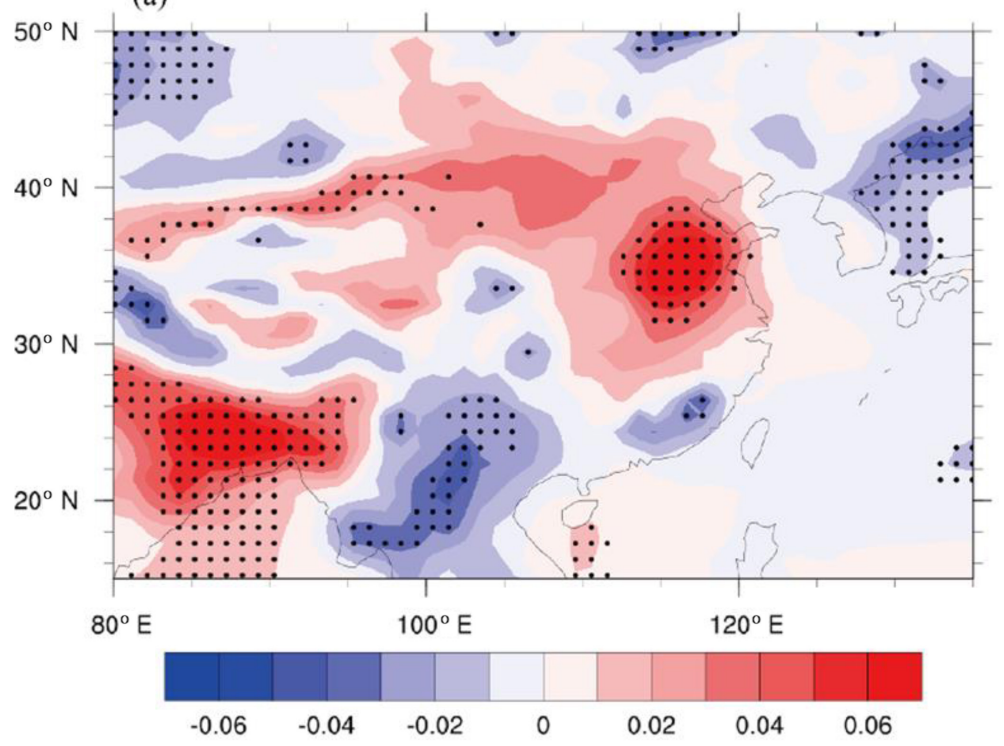

(b)

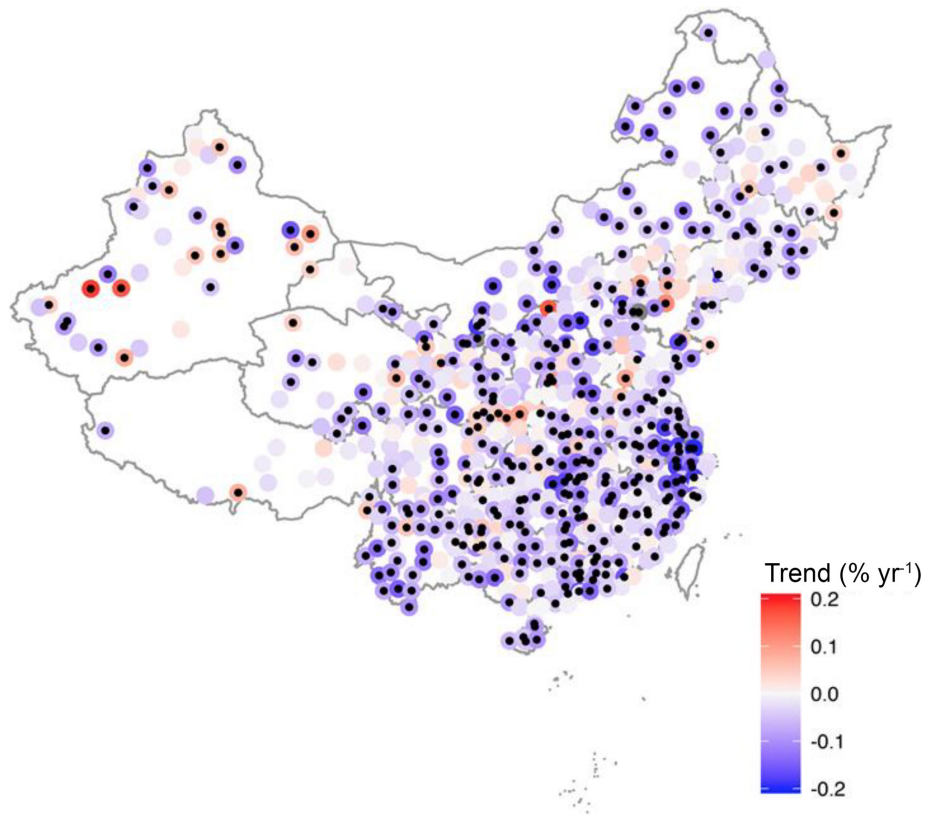

Figure 2. (a) Spatial distribution of linear trends of annual average RH (in $\% \mathrm{yr}^{-1}$ ) in China calculated for 1960-2017 historical simulations by an ensemble of 17 CMIP5 climate models; (b) same as (a) except derived from China Meteorological Administration (CMA) meteorological stations. Small black dots denote those trends significant at $95 \%$ confidence level. 
Table 1. Abbreviation and name of 17 CMIP5 models used in this study.

\begin{tabular}{ll}
\hline Abbreviation & Expanded model name \\
\hline ACCESS1-0 & $\begin{array}{l}\text { Commonwealth Scientific and Industrial Research Organisation Australian Community, } \\
\text { Climate and Earth System, version 1.0 } \\
\text { Commonwealth Scientific and Industrial Research Organisation, Australian Community, } \\
\text { Climate and Earth System, version 1.3 }\end{array}$ \\
CNRM-CM5 & Centre National de Researches Météorologiques Coupled Global Climate Model, version 5 \\
CSIRO-Mk3-6-0 & Commonwealth Scientific and Industrial Research Organisation Mark, version 3.6.0 \\
CanESM2 & The second-generation Canadian Earth System Model \\
FGOALS-S2 & The Flexible Global Ocean-Atmosphere-Land System model, spectral version 2 \\
HadGEM2-AO & Atmosphere and Ocean (non-Earth System version) configuration of HadGEM2 \\
HadGEM2-CC & Hadley Global Environment Model 2 - Carbon Cycle \\
HadGEM2-ES & Hadley Global Environment Model 2 - Earth System \\
INMCM4 & Institute of Numerical Mathematics Coupled Model, version 4.0 \\
MIROC-ESM-CHEM & An atmospheric-chemistry-coupled version of MIROC-ESM \\
MIROC-ESM & Model for Interdisciplinary Research on Climate Earth System Model \\
MIROC5 & Model for Interdisciplinary Research on Climate, version 5 \\
MRI-CGCM3 & Meteorological Research Institute Coupled Atmosphere-Ocean General Circulation Model, version 3 \\
MRI-ESM1 & Meteorological Research Institute - Earth System Model, version 1 \\
NorESM1-M & Norwegian Earth System Model, version 1, intermediate resolution \\
NorESM1-ME & Norwegian Climate Centre Earth System Model ME \\
\hline
\end{tabular}

CMIP5 climate models. This result is not surprising because it is well known that climate models have large uncertainties and biases in local and regional projections of trends of meteorological parameters. In fact, the evaluation of climate models during the Intergovernmental Panel on Climate Change (IPCC) Fifth Assessment Report (AR5) assessed medianand-above model performance only for the projected global average temperature trends (Flato et al., 2013).

Second, Fig. 1d of SHEN showed time series of monthly average $\mathrm{PM}_{2.5}$ and three meteorological parameters, i.e., $\mathrm{RH}$, V850, and PC1. The correlations among $\mathrm{PM}_{2.5}, \mathrm{RH}, \mathrm{V} 850$, and PC1 are very good as reported in SHEN. However, most of the good correlations are contributed by the large monthly variations. Will the good correlations hold true for yearly variations, and more importantly, will they hold for the timescale of climate change, which is the timescale of concern for SHEN? In addition, will the ratios between $\mathrm{PM}_{2.5}$ and the three meteorological parameters of longer timescales remain the same as those derived from monthly data? SHEN did not address these questions. Here we reproduce Fig. 1d of SHEN in Fig. 3a. Correlation coefficients of $\mathrm{PM}_{2.5}$ with $\mathrm{PC} 1$, V850, and RH derived from Fig. 3a are 0.90, 0.81, and 0.79 respectively, consistent with SHEN. In comparison, Fig. 3b shows yearly average values of $\mathrm{PM}_{2.5}, \mathrm{PC} 1, \mathrm{~V} 850$, and $\mathrm{RH}$; their corresponding correlation coefficients are 0.80, 0.66, and 0.46 respectively. These yearly values are significantly smaller than the monthly values, casting serious doubt on the applicability of results of monthly correlation to longer timescales. A further issue is that SHEN did not document which parameters were used in the principal component analysis and how PC1 was derived.
Third, a more fundamental question is that a parameter such as PC1 should not be considered to be a sole, exclusive, or sufficient proxy of $\mathrm{PM}_{2.5}$ just because $\mathrm{PC} 1$ has a good correlation with $\mathrm{PM}_{2.5}$. Even a perfect correlation coefficient (1.0) does not imply any causal relationship, let alone an exclusive or sufficient relationship. In other words, PC1, V850, or RH should not be used to exclude other proxies such as those suggested by Wang et al. (2015), Cai et al. (2017), Zou et al. (2017), and Li et al. (2018). The exclusiveness (or sufficient condition) of an index can only be established if a mechanistic model that uses the index as a sole proxy can successfully reproduce the concentrations and trend of $\mathrm{PM}_{2.5}$ quantitatively. SHEN did not develop such a model. For example, the variation in severe haze is associated with the daily variation in weather condition, as shown in Cai et al. (2017), instead of the monthly PC1 given by SHEN. By using the same data as in SHEN, the correlation coefficient of PC1 with $\mathrm{PM}_{2.5}$ on a daily basis is 0.68 (Fig. 4b), which is significantly lower than the monthly value of 0.90 in Fig. 4a, demonstrating that different correlation coefficients are found at different timescales again. Furthermore, the correlation coefficient of $\mathrm{PC} 1$ with $\mathrm{PM}_{2.5}$ for severe haze days (days with daily mean $\mathrm{PM}_{2.5}$ concentration $\geq 150 \mu \mathrm{g} \mathrm{m}^{-3}$, as defined in Cai et al., 2017) is a small value of 0.34 (Fig. 4c). Therefore, it is inappropriate to use the monthly PC1 to predict future severe winter haze pollution in Beijing as in SHEN. Compared to the large uncertainties in regional RH from the climate models in SHEN, the haze weather index (HWI) in Cai et al. (2017) is defined by anomalies in large-scale circulation with a three-dimensional dynamical concept, which can be captured by climate models 
(a) Monthly time series for $2010-2017$

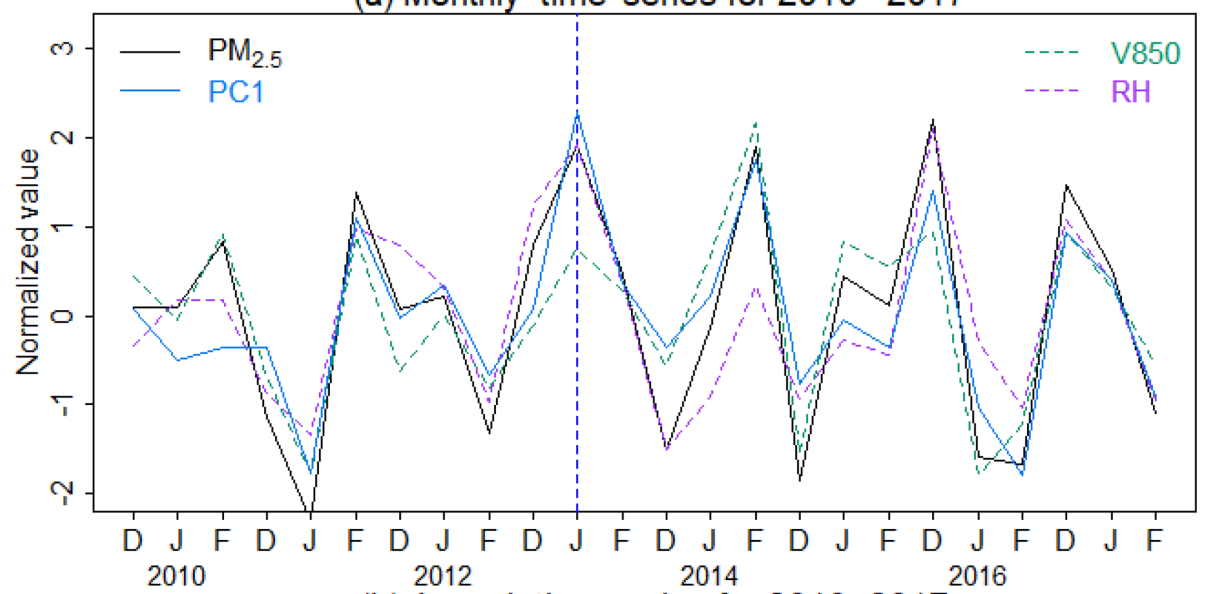

(b) Annual time series for 2010-2017

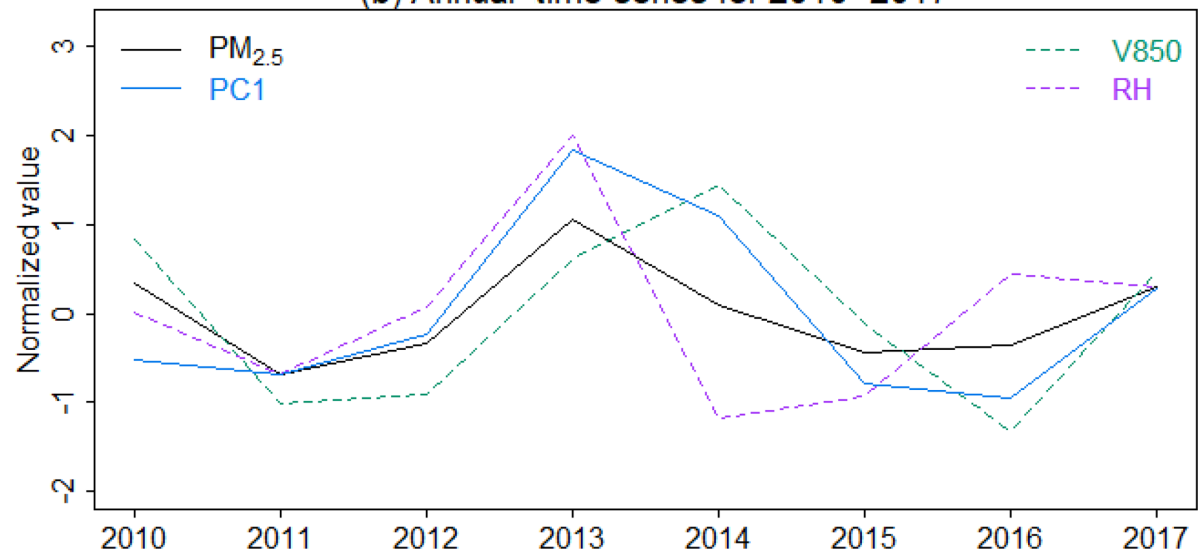

Figure 3. (a) Monthly mean time series for 2010-2017 of normalized PC1, $\mathrm{PM}_{2.5}$, V850, and RH. The normalization is relative to the 2010-2017 means; (b) same as (a) except for yearly means.

(a)

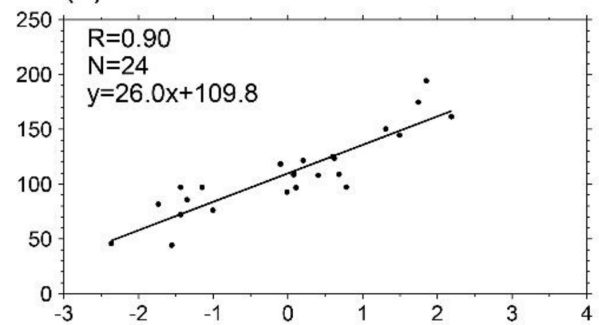

(c) (b)

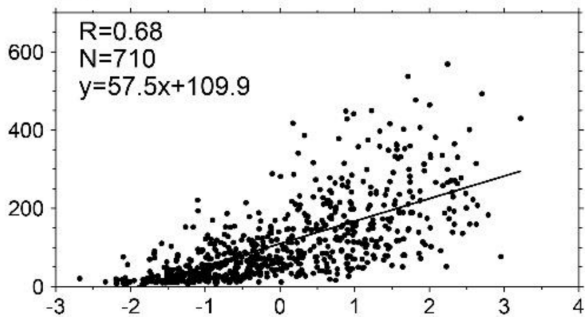

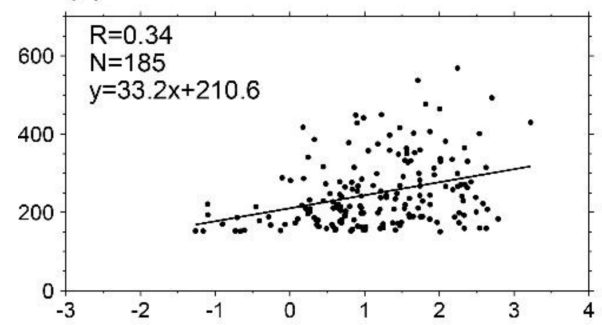

Figure 4. Correlations between PC1 (defined by V850 and RH in SHEN; horizontal axis) with observed wintertime $\mathrm{PM}_{2.5}$ concentrations in Beijing $\left(\mu \mathrm{g} \mathrm{m}^{-3}\right.$; vertical axis) for (a) monthly $\mathrm{PM}_{2.5}$ concentrations and $\mathrm{PC} 1$, (b) daily $\mathrm{PM}_{2.5}$ concentrations and $\mathrm{PC} 1$, and (c) daily $\mathrm{PM} 2.5$ concentrations and PC1 for severe haze days (daily mean $\mathrm{PM}_{2.5} \geq 150 \mu \mathrm{g} \mathrm{m}^{-3}$ ). In each panel, $N$ is the number of samples in the studied time period of 2010-2017 as in SHEN, and $R$ is the correlation coefficient. 
for the past and future (see Cai et al., 2017, for the justification).

Data availability. The CMIP5 model results provided by World Climate Research Programme (http://cmip-pcmdi.llnl.gov/cmip5/, last access: 31 January 2019, Taylor et al., 2012) are available. The data of this paper are available upon request to Shaw Chen Liu (shawliu@jnu.edu.cn).

Author contributions. RL, LM, and SL performed most the analysis. RL, SL, and HL prepared the paper, with contributions from all co-authors.

Competing interests. The authors declare that they have no conflict of interest.

Financial support. This research has been supported by the National Natural Science Foundation of China (grant no. 91644222) and the Environmental Public Welfare Industry in China (grant no. 201509001).

Review statement. This paper was edited by Bryan N. Duncan and reviewed by one anonymous referee.

\section{References}

Cai, W., Li, K., Liao, H., Wang, H., and Wu, L.: Weather conditions conducive to Beijing severe haze more frequent under climate change, Nat. Clim. Change, 7, 257-262, https://doi.org/10.1038/nclimate3249, 2017.

Flato, G., Marotzke, J., Abiodun, B., Braconnot, P., Chou, S. C., Collins, W., Cox, P., Driouech, F., Emori, S., Eyring, V., Forest, C., Gleckler, P., Guilyardi, E., Jakob, C., Kattsov, V., Reason, C., and Rummukainen, M.: Evaluation of Climate Models, in: Climate Change 2013: The Physical Science Basis. Contribution of Working Group I to the Fifth Assessment Report of the Intergovernmental Panel on Climate Change, edited by: Stocker, T. F., Qin, D., Plattner, G.-K., Tignor, M., Allen, S. K., Boschung, J., Nauels, A., Xia, Y., Bex, V., and Midgley, P. M., Cambridge University Press, Cambridge, UK, New York, NY, USA, 2013.

Li, K., Liao, H., Cai, W., and Yang, Y.: Attribution of anthropogenic influence on atmospheric patterns conducive to recent most severe haze over eastern China, Geophys. Res. Lett., 45, 20722081, https://doi.org/10.1002/2017GL076570, 2018.

Mao, L., Liu, R., Liao, W., Wang, X., Shao, M., Liu, S., and Zhang, Y.: An observation-based perspective of winter haze days in four major polluted regions of China, Natl. Sci. Rev., 6, 515-523, https://doi.org/10.1093/nsr/nwy118, 2018.

Shen, L., Jacob, D. J., Mickley, L. J., Wang, Y., and Zhang, Q.: Insignificant effect of climate change on winter haze pollution in Beijing, Atmos. Chem. Phys., 18, 17489-17496, https://doi.org/10.5194/acp-18-17489-2018, 2018.

Taylor, K., Stouffer, R., and Meehl, G.: An overview of CMIP5 and the experiment design, B. Am. Meteorol. Soc., 93, 485-498, https://doi.org/10.1175/BAMS-D-11-00094.1, 2012.

Wang, H., Chen, H., and Liu, J.: Arctic sea ice decline intensified haze pollution in eastern China, Atmos. Ocean. Sci. Lett., 8, 1-9, https://doi.org/10.3878/AOSL20140081.

Zou, Y., Wang, Y., Zhang, Y., and Koo, J. H.: Arctic sea ice, Eurasia snow, and extreme winter haze in China, Sci. Adv., 3, e1602751, https://doi.org/10.1126/sciadv.1602751, 2017. 